\title{
HOUSEHOLD DRINKING WATER STORAGE INTERVENTION TO ASSESS ITS IMPACT ON WATER QUALITY AT MAE LA TEMPORARY SHELTER
}

Valerie Daw Tin Shwe ${ }^{1, *}$, Ratana Somrongthong ${ }^{1}$, Robert Sedgwick Chapman ${ }^{1}$

${ }^{1}$ College of Public Health Sciences, Chulalongkorn University, Bangkok, Thailand.

Received: 6 May, 2018

Accepted: 14 Sept, 2019

Published: 17 Sept, 2019

Key words: Diarrhea; Household drinking water; Mae La temporary shelter; Safe storage; Thailand.

*Correspondence to: Valerie Daw Tin Shwe, Chulalongkorn University, Bankok. Email: valerie.dr.@gmail.com

DOI:https://doi.org/10.3126/jcmc.v9i3.25776

\section{Citation}

Tin Shwe VD, Somrongthong R, Chapman RS. Household drinking water storage intervention to assess its impact on water quality at Mae La temporary shelter. Journal of Chitwan Medical College 2019; 9(29):3-14.

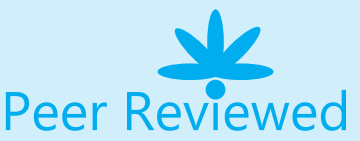

\section{ABSTRACT}

Background: Diarrhoea cases make up nearly two-thirds of total clinic visits at Mae La temporary shelter, Thailand, $40 \%$ being under five diarrhoeal cases. The use of a safe storage container for drinking water may prevent contamination and reduce diarrhoeal disease morbidity in camp residents. The aim of this study was to evaluate the use of safe drinking water storage containers and diarrhoeal diseases in under 5 children at the Mae La temporary shelter.

Methods: A randomized controlled trail was conducted in 400 households with at least one child under 5 years old over a period of four months. Intervention households received safe containers, while control households did not. Households were visited twice weekly during the three-month follow-up. Recent occurrence of diarrhoea in children under five was ascertained and residual chlorine levels in drinking water were measured. The results were analyzed by chi-square tests and survival analyses.

Results: Overall, the study found a $75 \%$ reduction of under five diarrhoea in the intervention group and 3.5-times less risk than control group subjects. Key factors associated with under five diarrhoea were: study group participation, no formal education of household primary caregivers; main sources of acquired drinking water; awareness regarding tap water chlorination; length of time living in camp

Conclusions: In conclusion, intervention group participants were found to experience a reduction in diarrhoea morbidity when compared to their control group counterparts. E. coli contamination of drinking water was very common, suggesting little or no protection from chlorination.

\section{INTRODUCTION}

Diarrhoea is an important disease, burden of disease, and health costs, but also because it can be prevented by behavioral changes and appropriate treatment technology. Contaminated drinking water is a principal cause of the diarrhoeal disease that results in 2.5 million childhood deaths yearly. ${ }^{1}$ Poor morbidity and mortality diarrhoeal outcomes overwhelmingly remain confined to developing countries with significant infrastructure deficits. The ultimate solution is to provide communities access to systems of piped, disinfected water, but this 'public domain' approach is expensive and timeconsuming. To address immediate needs, other more practical approaches are required in order to ensure the safety of drinking water while long-term transformative progress is made in improving local infrastructure. In this context, study of 'domestic domain' transmission, corresponding to in-house contamination, is a definitely beneficial objective.

Access to a safe source alone does not ensure the ultimate quality of consumed water. Even if collected 
household water is of acceptable microbiological quality, it may become contaminated with pathogens of faecal origin at any point between collection, storage, serving or handling in homes, which is widely recognized as an issue of major public health

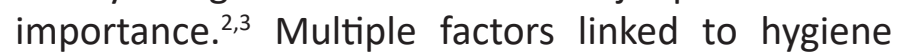
practices are primarily responsible, however, hands have the greatest potential to introduce contamination because of the constant risk of contact during household water management. ${ }^{4}$ Therefore, full health benefits are not possible in the absence of improved water storage and sanitation. ${ }^{5}$

Safe storage is a critical component of household water interventions, which includes the conditions and practices of water collection, storage, handling and choice of storage containers. ${ }^{6}$ In 1992, as a response to an outbreak of cholera in Latin America, the Centers for Disease Control and Prevention (CDC) and the Pan American Health Organization (PAHO) developed a household-based intervention to meet the immediate need for improved water quality. This Safe Water System is inexpensive, easily disseminated, and has the potential for recovering some of the costs of implementation. Over the last two decades it has been extensively field-tested and made an implementation priority by health service providers where identified vulnerable communities are found. The key to this strategy is to make drinking water safe through both disinfection and safe storage at the point of use.

Studies show that the use of containers with narrow openings for filling, and dispensing devices such as spouts or spigots protect the collected water during storage and household use. Improved containers protect stored household water from the introduction of microbial contaminants via contact with hands, dippers, other faecally contaminated vehicles or the intrusion of vectors. ${ }^{7}$ An early study recorded lower faecal coliform counts from containers with taps than from containers, from which water must be dipped. ${ }^{8}$ Other studies also report better water quality from containers designed to prevent handwater contact and require that water be poured. ${ }^{9}$ One systematic review study, describing the effect of safe storage alone on diarrhea, stated that there was a $69 \%$ reduction in the geometric mean of faecal coliform levels in household water and 31\% reduction in diarrhoeal disease in children under five years of age among the group using the improved bucket. ${ }^{10}$

A Honduran study reported an immediate deterioration in water quality as collection containers were filled, presumably caused by inadequate washing of the container, or by hand contact. ${ }^{11}$ In addition, different serving methods had a significant effect on water quality. Furthermore, the introduction of a special storage container in households to prevent contact of water with a serving utensil or hands significantly reduced diarrhoeal diseases and therefore has been widely advocated. ${ }^{10}$

The World Health Organization guidelines for drinking water quality, which consider water with no more than $10 \mathrm{E}$. coli/ $100 \mathrm{ml}$ to be of relatively low risk and of low priority for action, is also rated to be of low risk based on sanitary inspection. ${ }^{12}$ Water containing coliform or $E$. coli should not be used for drinking or cooking unless boiled for 5 to 10 minutes or otherwise disinfected. The presence of $E$. coli indicates that the water has been contaminated with faeces and the risk of contracting an infectious disease is much greater than when only total coliform are present. ${ }^{13}$ In summary, these organisms are good indicators of the potential contamination of a water source. Tests for coliform bacteria have been used to evaluate the general quality of water. ${ }^{14}$

\section{SITUATION ANALYSIS: MAE LA CAMP}

The Mae La temporary shelter is located in Tha Song Yan District, Tak province, Thailand about $8 \mathrm{~km}$ from the Thai-Myanmar border and approximately 57 kilometers north of Mae Sot. The temporary shelter was established in the 1970s with an area of 4 square kilometers with a traditional, village-like atmosphere, as planned by the refugee communities themselves. At the present time there are 8,426 households with a total population of 46,292 . It is a relatively large camp with the area divided into 3 zones (A, B, and C) and further sub-divided into a total of 16 sectors without barriers between sections.

The Phanu River is the principal source of water. An NGO, Solidarities, develops and maintains the existing water system providing 'public domain' access to drinking and domestic water. The drinking 
water network is from the river, 13 springs and 181 taps. There are 17 boreholes and 65 domestic wells. The water in the reservoir is chlorinated daily. The turbidity and free residual chlorine are monitored daily at source. Microbiological quality of water at source is analyzed monthly. Water is distributed to residents by standpipes two times a day, typically for about two hours early in the morning and around two hours in the afternoon. The average distribution is 20 liters per day per inhabitant. At times, residents use their nearest water source, typically surface water or well water if they live far from a tap.

Domestic water storage is required because tap water is provided only intermittently in the camp. Collection containers are usually rinsed before filling. In the case of buckets, hands are often rubbed around the inside while rinsing. Therefore hand and water contact is frequently observed as excess water is scooped out, as containers are moved from under the pump, and when they are lifted onto the heads of collectors. Plastic buckets are the most common type of collection container but some households use jerry cans.

All families store household drinking water in widemouthed plastic or clay pots containers without spigots. Wide-mouthed containers are preferred to store drinking water because they are easier to clean. Water is either poured from the drinking water storage container, or scooped from the container using a cup. People cannot avoid touching water when they use a cup or ladle to dip it out, so there is contamination potential during household usage.

Most households follow similar practices for collection, household storage and use of drinking water. Washing hands with soap is an uncommon practice among residents in the camp. Most latrines are inside the houses and close to the water that is used for washing.

The most common diseases in the camp are acute respiratory tract infections, diarrhoeal diseases and skin infections. Diarrhoea has been endemic in Mae La especially among children under five years old. A total of 9,089 cases of diarrhoeal diseases, including watery diarrhoea, dysentery, and cholera cases, were reported in 2007. These diarrhoea cases constituted $66 \%$ of total clinic visits with $40 \%$ of such cases contracted by children under five.
A cholera outbreak occurred the following year in 2008. Among 299 cases (attack rate of 6.1/1000) identified $37 \%$ were laboratory confirmed as Vibrio cholera 01, El Tor Inaba. The MoPH, Thailand, Centers for Disease Control and Prevention (CDC), and the Thai MoPH-CDC Collaboration office investigated cholera outbreak risk factors. Their findings identified that chlorine residual was adequate in the taps, but not in wells. Among 56 cases and 112 controls, cholera was associated with drinking well water $(\mathrm{OR}=3.8,95 \% \mathrm{Cl}=1.1,13.1)$, using well water for washing ( $\mathrm{OR}=3.1,95 \% \mathrm{Cl}=1.3,8.4)$, and eating food from street vendors $(\mathrm{OR}=3.2,95 \% \mathrm{Cl}=1.1$, 6.3). ${ }^{15}$ nother cholera outbreak occurred from 24 May to 19 November 2010. There were 216 suspected cases and another 362 confirmed cases of cholera in the camp hospital. The attack rate was 11.76 (per 1,000 pop). Meanwhile, active case findings resulted in an additional 161 confirmed cases. These cases were all laboratory confirmed as Vibrio cholera 01 Ogawa except for one case which was identified as Vibrio cholera $\mathrm{O} 1 \mathrm{Inaba}$ at the end of the outbreak.

\section{METHODS}

A cluster randomized controlled trial (CRCT) was conducted among a total of 400 households in Zone C of the Mae La Temporary Shelter which is situated at Tha Song Yan District, Tak province, Thailand about $8 \mathrm{~km}$ from the Thai-Myanmar border (where is it located???) between October 2009 and March 2010. Each household had at least one child under 5 years old. The purpose of the intervention study was to measure the impact of safe water containers on reduction of diarrhoeal diseases. The reason for selecting the site was more burden of diarrhoeal cases was seen in this shelter in comparison to other camps

Zone $\mathrm{C}$ is relatively large compared to other zones in the refugee camp and houses about $40 \%$ of the total camp population. There are 74 taps, 11 boreholes and 28 domestic wells in Zone C. While only tap water is chlorinated, a given household often has multiple sources of water. Family socio-economic and demographic characteristics, hygienic habits, and water handling practices are similar throughout the 7 sectors in Zone C, as well as similar to other zones across the camp. 
In zone C, among 3,700 households with a total population of 19,654 , there were 2,312 children under five years old in 1,150 households. A March 2009 Zone C community-based study revealed the diarrhoea incidence rate to be $12 \%$ for children under five years of age and 3\% for all age groups, both of which are considerably higher than hospitalbased rates. These statistics included repeated cases of diarrhoea in individual children.

A total sample size of 606 children was calculated for intervention and control groups for the study period using Epi Info version 6, Statcalc, while assuming that the monthly diarrhoeal attack rate would be $12 \%$ for children under five years of age in the control group. A reduction in diarrhoea risk of $30 \%$ and a $70 \%$ annual incidence among children in intervention households were estimated with a confidence of $95 \%$ and statistical power of $80 \%{ }^{10}$
As there was an average of about 2 children under five years old in households, 300 households were selected for this study. To account for the possibility that some households would drop out of this study, 100 additional households were added to the 300 resulting in a total of 400 households with children under five years old to be monitored, approximately half as the intervention group and the other the basis for the control group.

Half of the participants received a safe storage drinking water container while only the control group was observed. Field workers used a structured questionnaire to collect baseline measures, as well as follow-up study data through twice weekly household visits to record any incidence of diarrhea in under five children. All field workers had to be able to read and write Burmese as well as able to speak and understand the Karen language.

Four hundred out of $\mathbf{1 1 5 0}$ household s with children under 5 years old were randomely selected. They were then randomized into an intervention and control group (Figure 1).

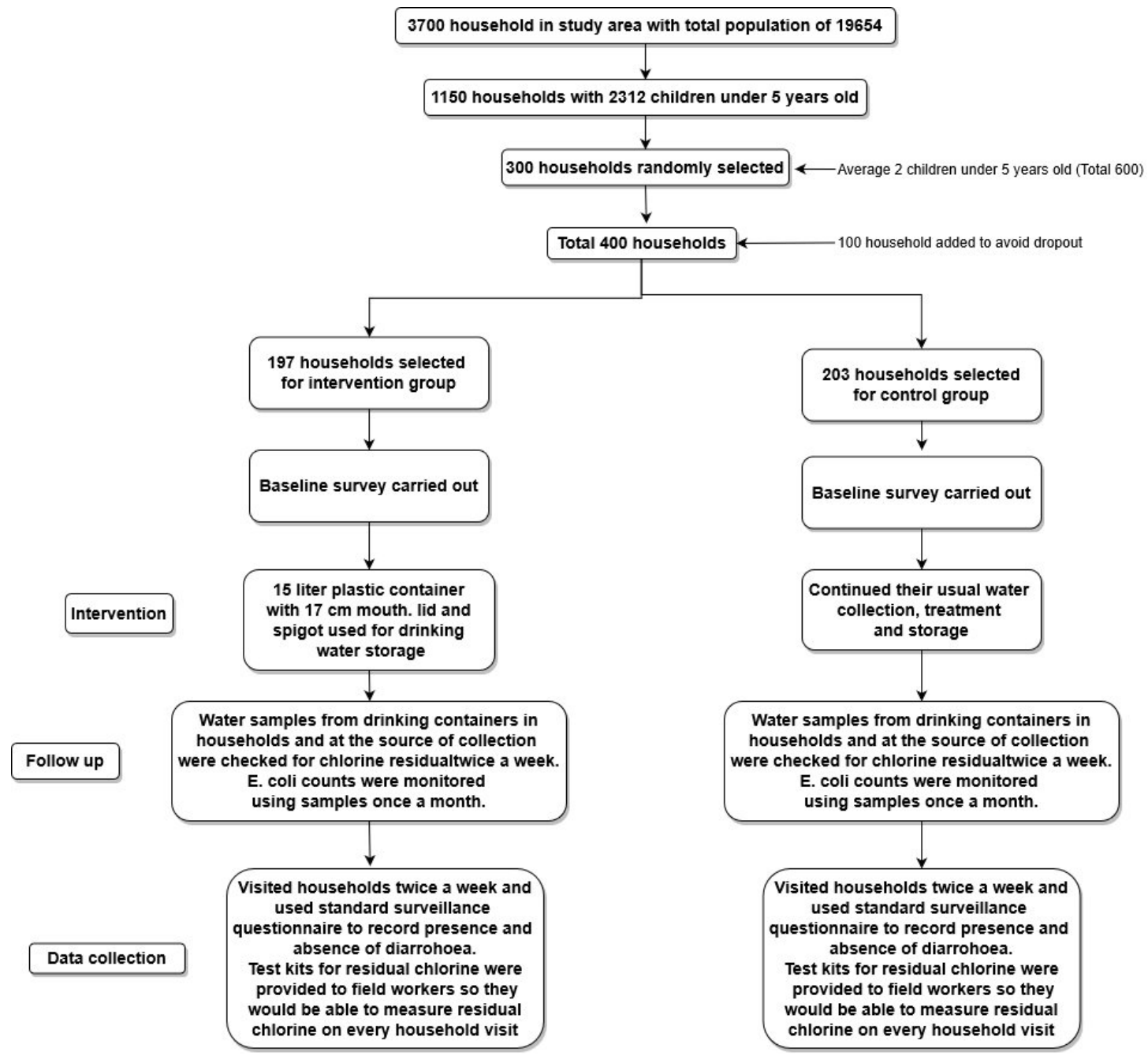

Figure 1: Trial Profile 
During household visits, field workers measured residual chlorine levels using $\mathrm{V}$ UNIQUE v-color 9720 test kits. In addition, Escherichia coli (E. coli) levels across study groups' drinking water were also monitored twice monthly using the MultipleTube Fermentation Technique (MTFT). At the study's conclusion, control group households were provided with their own safe storage drinking water containers.

Diarrhoea was defined as three or more loose stools or one bloody stool during a 24-hour period. A diarrhoea episode was marked as a new episode if the person had had at least three days without diarrhoea since the previous episode. ${ }^{16}$

The principal researcher made unannounced visits to $5 \%$ of households already visited by field workers each week and reviewed the history of diarrhoea among family members. The data collected by the supervisor was compared to that collected by the field worker and if there was a difference, the field worker and supervisor revisited the house together in order to resolve this difference whenever feasible.

Subjects' characteristics were analyzed at both baseline and post-intervention using bivariate Table 1: Social demographic characteristics $(N=400)$ analysis. The effect of handling and personal hygiene practices, along with the social culture of each family's home life which could affect the quality of drinking water after storage, were all recorded and considered covariates in the intervention study.

Bivariate analysis was undertaken to determine relevant predictors to be used in a survival analyses based on logistic regression models. A multivariable Cox model was applied without assumption that the follow up study would start immediately after baseline.

\section{RESULTS \\ Baseline}

Table 1 showed the results of baseline characteristics of the study ( $N=400$ refers to the number of households). The comparison of all relevant variables in both intervention and control groups before the intervention was done using the Pearson chi-square (independent group/unmatched comparison) method. However, some variables required use of the Kruskal Wallis Rank sum test and these $p$-values are identified with an asterisk. Out of the 400 households surveyed, there were 127 (32\%) adult male household respondents and 273 (68\%) adult female household respondents $(p=0.781)$.

\begin{tabular}{|c|c|c|c|}
\hline Characteristics & $\begin{array}{l}\text { Intervention } \\
(\mathrm{N}=197)\end{array}$ & $\begin{array}{l}\text { Control } \\
(\mathrm{N}=203)\end{array}$ & p-value \\
\hline \multicolumn{4}{|c|}{ (1v-1) } \\
\hline Male & $64(32.5)$ & $63(31.2)$ & 0.781 \\
\hline Female & $133(67.5)$ & $140(68.9)$ & \\
\hline \multicolumn{4}{|l|}{ Number of occupants } \\
\hline Median & 6 & 6 & $0.399 *$ \\
\hline Min., Max & 2,14 & 3,18 & \\
\hline IQR & 5,7 & 5,8 & \\
\hline \multicolumn{4}{|l|}{ Number of children under five } \\
\hline Median & 1 & 1 & $0.432 *$ \\
\hline Min., Max & 1,5 & 1,4 & \\
\hline IQR & 1,2 & 1,2 & \\
\hline \multicolumn{4}{|l|}{ Number of years in current house } \\
\hline Median & 4 & 5 & $0.235^{*}$ \\
\hline Min., Max & 1,23 & 1,23 & \\
\hline IQR & 2,10 & 2,10 & \\
\hline Number of years in Mae La Camp & & & $0.417^{*}$ \\
\hline Median & 10 & 12 & \\
\hline Min., Max & 1,28 & 1,26 & \\
\hline IQR & 7,20 & 9,19 & \\
\hline \multicolumn{4}{|l|}{ Education } \\
\hline None & $79(40.1)$ & $88(44.7)$ & 0.359 \\
\hline$\geq$ Primary & $118(59.9)$ & $109(55.3)$ & \\
\hline
\end{tabular}

* Kruskal Wallis Rank sum test 
At baseline, only one drinking water source characteristic was found to be statistically significant between the intervention and control groups. Specifically this was a difference between the study groups relative to their own household awareness of whether NGO-tap water was considered a "treated", therefore a safe, drinking water source $(p=0.023)$ (Table 2).

Table 2: Drinking water $(\mathrm{N}=400)$

\begin{tabular}{|c|c|c|c|}
\hline Characteristics & $\begin{array}{l}\text { Interventio } \\
(\mathrm{N}=197)\end{array}$ & $\begin{array}{l}\text { Control } \\
(\mathrm{N}=203)\end{array}$ & p-value \\
\hline \multicolumn{3}{|l|}{ Usual source } & 0.884 \\
\hline NGO tap water & $117(60.6)$ & $121(59.9)$ & \\
\hline Others & $76(39.4)$ & $81(40.1)$ & \\
\hline \multicolumn{3}{|l|}{ Other sources } & 0.141 \\
\hline Yes & $57(29.4)$ & $45(22.8)$ & \\
\hline No & $137(70.6)$ & $152(77.2)$ & \\
\hline \multicolumn{3}{|l|}{ Treatment } & 0.221 \\
\hline Yes & $182(94.3)$ & $184(91.1)$ & \\
\hline No & $11(5.7)$ & $18(8.9)$ & \\
\hline \multicolumn{3}{|l|}{ Chlorination } & 0.139 \\
\hline Yes & $23(11.8)$ & $15(7.4)$ & \\
\hline No & $172(88.2)$ & $187(92.6)$ & \\
\hline Awareness of NGO tap water treatment & & & 0.023 \\
\hline Yes & $111(56.9)$ & $138(68.0)$ & \\
\hline No & $84(43.1)$ & $65(32.0)$ & \\
\hline \multicolumn{3}{|l|}{ Possibility of domestic chlorination } & 0.243 \\
\hline Yes & $82(48.0)$ & $73(41.7)$ & \\
\hline No & $89(52.0)$ & $102(58.3)$ & \\
\hline \multicolumn{3}{|l|}{ Usage of chlorinated drinking water } & 0.695 \\
\hline Yes & $49(25.5)$ & $54(27.3)$ & \\
\hline No & $143(74.5)$ & $144(72.7)$ & \\
\hline
\end{tabular}

Two knowledge characteristics were found to be either statistically or marginally statistically significant at baseline between intervention and control groups. Actual statistical significance was associated with whether or not the household's primary caregiver of children under five years knew of at least one pre-determined diarrhoea prevention strategy $(p=0.048)$. Another knowledge characteristic was related to the primary caregivers' comprehension of the meaning of diarrhoea $(p=0.054)$ (Table 3).
Follow-up study analysis of all independent predictors was undertaken to determine their associative effects upon diarrhoeal incidence. Two such characteristics yielded statistically significant results with the strongest predictor of under five diarrhoea outcomes, by far, being the study group for which participants were within (intervention vs. control; $p=<0.001$ ) (Table 4). Statistical significance was also found between the association of whether or not household primary caregivers of under five children had any formal education $(p=0.021)$. 
Table 3: Knowledge of diarrhoeal diseases $(\mathrm{N}=400)$

\begin{tabular}{|l|c|c|c|}
\hline \multicolumn{1}{|c|}{ Characteristics } & $\begin{array}{c}\text { Intervention } \\
(\mathrm{N}=197)\end{array}$ & $\begin{array}{c}\text { Control } \\
(\mathrm{N}=203)\end{array}$ & p-value \\
\hline Awareness of meaning of diarrhoea & $181(92.8)$ & $197(97.0)$ & 0.054 \\
\hline Yes & $14(7.2)$ & $6(3.0)$ & \\
\hline No & & & \\
\hline Knowledge on prevention of diarrhoea & $143(84.1)$ & $155(91.2)$ & 0.048 \\
\hline Yes & $27(15.9)$ & $15(8.8)$ & \\
\hline No & & & 0.958 \\
\hline Education on diarrhoeal diseases & $175(90.2)$ & $181(90.0)$ & \\
\hline Yes & $19(9.8)$ & $20(10.0)$ & \\
\hline No & & & \\
\hline
\end{tabular}

Table 4: Social demographic characteristics $(N=400)$

\begin{tabular}{|c|c|c|c|}
\hline \multirow[b]{2}{*}{ Characteristics } & \multicolumn{2}{|c|}{ Diarrhoea } & \multirow{2}{*}{$\begin{array}{l}\text { Hazard Ratio } \\
(95 \% \mathrm{Cl}) \\
{[\mathrm{p}]}\end{array}$} \\
\hline & $\begin{array}{c}\text { Yes } \\
N=65 \\
(19.4 \%)\end{array}$ & $\begin{array}{c}\text { No } \\
N=335 \\
(83.7 \%)\end{array}$ & \\
\hline \multicolumn{4}{|l|}{ Age of head of households } \\
\hline$\leq 45 \mathrm{yr}$ & $52(80.0)$ & $276(82.4)$ & 1.0 \\
\hline$>45 \mathrm{yrs}$ & $13(20.0)$ & $59(17.6)$ & $\begin{array}{c}1.1(0.6-2.1) \\
{[0.699]}\end{array}$ \\
\hline \multicolumn{4}{|l|}{ Number of occupants } \\
\hline$<5$ & $16(17.0)$ & $78(83.0)$ & $\begin{array}{c}1.1(0.6-1.9) \\
0.814]\end{array}$ \\
\hline$\geq 5$ & $49(16.0)$ & $257(84.0)$ & 1.0 \\
\hline \multicolumn{4}{|l|}{ Number of children under five } \\
\hline 1 & $37(15.4)$ & $203(84.6)$ & 1.0 \\
\hline$\geq 2$ & $28(17.7)$ & $130(82.3)$ & $\begin{array}{c}1.2(0.7-1.9) \\
{[0.564]}\end{array}$ \\
\hline \multicolumn{4}{|l|}{ Number of years in current home } \\
\hline$\leq 1 \mathrm{yr}$ & $7(15.2)$ & $39(84.8)$ & 1.0 \\
\hline$>1 \mathrm{yrs}$ & $55(16.7)$ & $275(83.3)$ & $\begin{array}{c}1.0(0.5-2.3) \\
{[0.902]}\end{array}$ \\
\hline \multicolumn{4}{|l|}{ No. of years in Mae La camp } \\
\hline$\leq 1 \mathrm{yr}$ & $2(40.0)$ & $3(60.0)$ & 1.0 \\
\hline$>1 \mathrm{yrs}$ & $63(16.0)$ & $331(84.0)$ & $\begin{array}{c}0.3(0.1-1.2) \\
{[0.081]}\end{array}$ \\
\hline \multicolumn{4}{|l|}{ Education } \\
\hline None & $36(21.6)$ & $131(78.4)$ & 1.0 \\
\hline$\geq$ Primary & $29(12.8)$ & $198(87.2)$ & $\begin{array}{c}0.6(0.3-0.9) \\
{[0.021]}\end{array}$ \\
\hline
\end{tabular}


Marginal statistical significance was associated with two different NGO-related drinking water predictors, as well as, two other independent variables. The actual source of drinking water itself, whether from a NGO-tap or "other source", was a marginally

\section{Table 5: Sources of drinking water $(\mathrm{N}=400)$}

\begin{tabular}{|c|c|c|c|}
\hline \multirow[b]{2}{*}{ Characteristics } & \multicolumn{2}{|c|}{ Diarrhoea } & \multirow[b]{2}{*}{$\begin{array}{c}\text { Hazard Ratio } \\
\qquad \begin{array}{c}(95 \% \mathrm{Cl}) \\
{[\mathrm{p}]}\end{array}\end{array}$} \\
\hline & $\begin{array}{c}\text { Yes } \\
N=65 \\
(19.4 \%)\end{array}$ & $\begin{array}{c}\text { No } \\
N=335 \\
(83.7 \%)\end{array}$ & \\
\hline \multicolumn{4}{|l|}{ Usual source } \\
\hline NGO tap water & 46 (19.3) & $192(80.7)$ & 1.0 \\
\hline Others & $18(11.5)$ & $139(88.5)$ & $\begin{array}{c}0.6(0.3-1.0) \\
{[0.052]} \\
\end{array}$ \\
\hline \multicolumn{4}{|l|}{ Other sources } \\
\hline Yes & $12(11.8)$ & $90(88.2)$ & 1.0 \\
\hline No & $53(18.3)$ & $236(81.7)$ & $\begin{array}{c}1.6(0.9-1.0) \\
{[0.135]}\end{array}$ \\
\hline \multicolumn{4}{|l|}{ Treatment } \\
\hline Yes & $58(15.8)$ & $308(84.2)$ & 1.0 \\
\hline No & $6(20)$ & $23(80)$ & $\begin{array}{c}1.3(0.6-3.1) \\
{[0.494]}\end{array}$ \\
\hline \multicolumn{4}{|l|}{ Chlorination } \\
\hline Yes & $4(10.5)$ & $34(89.5)$ & 1.0 \\
\hline No & $61(16.9)$ & $298(83.1)$ & $\begin{array}{c}1.6(0.6-4.4) \\
{[0.371]}\end{array}$ \\
\hline Yes & $4(10.5)$ & $34(89.5)$ & 1.0 \\
\hline \multicolumn{4}{|c|}{ Awareness of NGO tap water } \\
\hline Yes & $48(19.3)$ & $201(80.7)$ & 1.0 \\
\hline No & $17(11.4)$ & $132(88.6)$ & $\begin{array}{c}0.6(0.3-1.0) \\
{[0.056]} \\
\end{array}$ \\
\hline \multicolumn{4}{|c|}{ Possibility of domestic chlorination } \\
\hline Yes & $24(15.5)$ & $131(84.5)$ & 1.0 \\
\hline No & $34(17.8)$ & $157(82.5)$ & $\begin{array}{c}1.1(0.7-1.9) \\
{[0.636]}\end{array}$ \\
\hline \multicolumn{4}{|c|}{ Usage of chlorinated drinking water } \\
\hline Yes & $22(21.4)$ & $81(78.6)$ & 1.0 \\
\hline No & 42 (14.6) & $245(45.4)$ & $\begin{array}{c}0.7(0.4-1.1) \\
{[0.122]} \\
\end{array}$ \\
\hline
\end{tabular}

The length of time living in the camp (either less than one year or greater than or equal to one year) was a third marginally significant statistical factor for under five diarrhoea ( $p=0.081)$. A fourth factor, $E$. coli testing results of home drinking water containers, significant predictor for ve diarrhoea $(p=0.052)$. Likewise, knowledge of whether NGO-tap water was chlorine-treated was also a marginally significant predictor for under five diarrhoea $(p=0.056)$ (Table $5)$. 
Table 6: Tests for residual chlorine and $E$. coli in drinking water $(\mathrm{N}=400)$

\begin{tabular}{|c|c|c|c|}
\hline \multirow[b]{2}{*}{ Characteristics } & \multicolumn{2}{|c|}{ Diarrhoea } & \multirow{2}{*}{$\begin{array}{c}\text { Hazard Ratio } \\
(95 \% \mathrm{Cl}) \\
{[\mathrm{p}]}\end{array}$} \\
\hline & $\begin{array}{c}\text { Yes } \\
N=65 \\
(19.4 \%) \\
\end{array}$ & $\begin{array}{c}\text { No } \\
N=335 \\
(83.7 \%)\end{array}$ & \\
\hline \multicolumn{4}{|l|}{ Stored drinking water } \\
\hline Yes & $62(16.9)$ & 305 (83.1) & 1.0 \\
\hline No & $1(6.7)$ & $14(93.3)$ & $\begin{array}{c}0.3(0.1-2.4) \\
{[0.277]}\end{array}$ \\
\hline \multicolumn{4}{|l|}{ Residual chlorine (mg/L) } \\
\hline Yes $(>0)$ & $3(15)$ & $17(85)$ & $\begin{array}{c}0.9(0.3-28) \\
{[0.827]}\end{array}$ \\
\hline None (0) & $61(16)$ & $317(84)$ & 1.0 \\
\hline \multicolumn{4}{|l|}{ E. coli } \\
\hline Red (no E. coli) & $2(5.3)$ & $36(94.7)$ & $\begin{array}{c}0.3(0.1-1.2) \\
{[0.082]}\end{array}$ \\
\hline Others (brown/orange/yellow) & $62(17.2)$ & $298(82.8)$ & 1.0 \\
\hline
\end{tabular}

Separate bivariate analyses were undertaken to check for association between study group and E. coli measures. At baseline, both study groups were similar in their household drinking water composition as regards microbiological test results for E. coli $(p=0.276)$. In fact, there were actually more household cases of $E$. coli in the intervention group than compared to the control group (11.2\%,
8.0\%). Follow-up study results were then analyzed at both a mid-point of the intervention study and upon conclusion (week 5 and week 11). Curiously, water quality testing during week 5 (visit 10) revealed a rise in both study groups' drinking water quality, though the intervention group's negative test results for $E$. coli were significantly different than those of the control group $(p<0.001)$ (Table 7$)$.

Table 7: Tests for residual chlorine and $E$. coli in drinking water $(\mathrm{N}=400)$

\begin{tabular}{|l|c|c|c|}
\hline Characteristics & $\begin{array}{l}\text { Intervention } \\
(\mathbf{N}=197)\end{array}$ & $\begin{array}{l}\text { Control } \\
(\mathbf{N}=203)\end{array}$ & p-value \\
\hline Residual chlorine (mg/L) & & & $0.335^{*}$ \\
\hline Median & 0.0 & 0.0 & \\
\hline Min., Max & $0.0,2.0$ & $0.0,0.5$ & \\
\hline IQR & $0.0,0.0$ & $0.0,0.0$ & \\
\hline E. coli & & & 0.276 \\
\hline Red (no E. coli detected) & $22(11.2)$ & $16(8.0)$ & \\
\hline Others (brown/orange/yellow) & $175(88.8)$ & $185(92.0)$ & \\
\hline
\end{tabular}

* Kruskal Wallis Rank sum test

Final E. coli test results from resident household drinking water containers conducted on the $22^{\text {nd }}$ visit by field workers during week 11 showed the most dramatic variation between study groups $(p<0.001)$. The chi-square scores between groups demonstrated very high significance $\left(X^{2}=182.1\right)$. At the end of study the intervention group had $72.8 \%$ of households recording water quality $E$. coli results with "red" scores compared to control groups who had only $6.5 \%$ of households with this $E$. coli test result (Table 8). 
Table 8: E. coli tests with negative results by study group

\begin{tabular}{|l|c|c|c|c|c|c|}
\hline \multirow{2}{*}{$\begin{array}{l}\text { Absence of } E \text {. coli } \\
\text { (test reading of red) }\end{array}$} & \multicolumn{2}{|c|}{ Intervention } & \multicolumn{2}{c|}{ Control } & \multirow{2}{*}{$\mathrm{X}^{2}$} & p-value \\
\cline { 2 - 6 } Baseline & Cases & $\%$ & Cases & $\%$ & & 0.276 \\
\hline Visit 10 & 22 & $11.2 \%$ & 16 & $8.0 \%$ & 1.2 & $<0.001$ \\
\hline Visit 22 & 142 & $72.8 \%$ & 47 & $23.5 \%$ & 17.6 & $<0.001$ \\
\hline
\end{tabular}

Survival analysis was performed using an extended risks of diarrhea in children under five over time for Cox model with time-dependent covariate to test intervention group participants, relative to control for intervention effects throughout the study period. subjects (Table 9).

Results demonstrated diminishing overall hazard

Table 9: Cox model with time-dependent covariate

\begin{tabular}{|l|l|l|l|r|r|r|r|r|}
\hline & B & SE & Wald & df & p-value & \multicolumn{2}{l|}{$\begin{array}{l}\text { Exp(B), } \\
\text { odds } \\
\text { ratio }\end{array}$} & \multicolumn{2}{l|}{$\begin{array}{l}\text { 95.0\% Cl for odds } \\
\text { ratio }\end{array}$} \\
\hline & & & & & & & Lower & Upper \\
\hline $\begin{array}{l}\text { Intervention vs. } \\
\text { control }\end{array}$ & 1.45 & 0.625 & 5.388 & 1 & 0.02 & 4.262 & 1.253 & 14.494 \\
\hline $\begin{array}{l}\text { Time-dependent } \\
\text { covariate }\end{array}$ & -0.103 & 0.03 & 11.691 & 1 & 0.001 & 0.903 & 0.851 & 0.957 \\
\hline
\end{tabular}

Overall, the study found a $75 \%$ reduction of diarrhea in children under five in the intervention group and 3.5-times less risk than control group subjects. Hazard risk ratios across study group were considerably changed over time. Key factors associated with diarrhea in children under five were study group participation, lack of formal education of household primary caregivers, main sources of drinking water, NGO tap water chlorination knowledge, length of time living in camp, and E. coli drinking water test results. At study's end, E. coli water quality tests were 11-times improved by intervention.

\section{DISCUSSION}

Baseline measures revealed the most common method of drinking water treatment by residents was boiling. This, however, was primarily undertaken in order to remove unpleasant tasting chlorine additives, though most knew that boiling water did kill harmful germs. Furthermore, use of chlorine to disinfect the wells was not practiced so as to avoid complaints from others who shared the same well. Importantly, study participants seemed to not realize that this boiled water was at risk of subsequent recontamination through the use of improper containers which allow exposure to germs from unclean fingers and hands and cups.
After boiling the water, residents let it cool down and later transferred the water, while filtering it with cloth, into their drinking water containers. The majority of camp residents used affordable, lightweight and unbreakable plastic containers with lids, though without spigots, for storing their drinking water.

Just under a quarter of residents had their own flush type latrines located inside their homes. Most used public flush latrines located nearby because of space and financial limitations. NGO-built public flush type latrines were provided on the condition that each was to be shared with 18 neighbors. Around $20 \%$ of study participants across both groups used public pit latrines.

On each household visit, during both the baseline and follow-up study surveys, field workers were required to observe how family members accessed their drinking water by requesting a cup of water, thus determining if physical contact was made with water from the drinking water containers.

Finally the field workers tested the drinking water provided by families for residual chlorine and E. coli. In most cases, residual chlorine was not detected because families had removed it through boiling. 
When the same drinking water was tested for E. coli, it came out positive in most cases. This indicated that either the health-giving benefits of chlorine had been removed through boiling or that the boiled water had been re-contaminated due to improper handling using containers without spigots. Typically well water was not boiled and thus found to contain high levels of $E$. coli due to the proximity to latrines.

At the follow-up study's conclusion, intervention group participants were found to experience a $75 \%$ reduction in diarrhoea morbidity when compared to their control group counterparts $(p<0.001)$. The fact that only $7.1 \%$ of intervention households experienced under five diarrhoea compared to a $25.1 \%$ under five diarrhoea morbidity in the control group can also be interpreted as a 3.5 times increased risk. This demonstrates a profound intervention effect which is most likely to have occurred due to the introduction of household-safe sealed drinking water containers, thus protecting the microbiological quality of household drinking water with direct positive impacts upon diarrhoea morbidity.

The admission of education level by primary caregivers into simple categories of either no formal education or at-least primary-school educated was an independent predictor of diarrhoea incidence in children under five $(p=0.021)$. Nearly $90 \%$ of all households with at least a primary school educated caregiver were immune from diarrhoea cases of children under five, whereas caregivers without any formal education experienced only about $80 \%$ of this protection, a basic doubling of risk. These results suggest a formidable distinction between the educational status of primary caretakers within the household and diarrhoea morbidity in children under five, on one hand, as well as illuminate possible target populations to focus parallel interventions.

Overwhelmingly, all but 2 cases of diarrhoea in children under five were reported as occurring within households where positive testing of E. coli bacteria in drinking water containers was also detected. $(p=0.082)$. Both a household's main source of drinking water $(p=0.052)$ and their knowledge of whether NGO tap water is treated (Yes or No) $(p=0.056)$ were marginally significant independent predictors for under five diarrhoea outcomes. A final predictor, too, may be instructive for demonstrating how more recently arrived households (less than 1 year in the camp) are at an increased risk for contracting under five diarrhoea ( 2.5 times; $p=0.081$ ).

Since the end of the study, $99 \%$ of intervention participants have reported continued use of the containers provided by the study because they realized the health benefits, specifically the reduction of diarrhoea. Others expressed satisfaction with the ease of water access

During the cholera outbreak beginning in May 2010, the 400 households in this study were followed up to detect any cases of cholera. However, there was no incidence of cholera in either the intervention or control group. Soon afterward, an NGO found out about this study's preliminary results and decided to distribute similar safe drinking water containers to all 8,000 households in the camp. Continued monthly random $E$. coli testing throughout the camp noted a substantial increase in the negative test results for E. coli of household drinking water following this distribution and usage of new water containers, further confirming the effectiveness of safe drinking water containers.

During the evaluation period, it was discovered that most of those who received the wide- mouthed containers with lids from this study preferred them to the narrow-mouthed containers which were massdistributed. This was because the wide- mouthed containers allowed much easier cleaning.

Recommendations from this study are a) Continue safe-storage drinking water distribution and maintenance; b) Additional support targeting should incorporate study findings relative to group characteristics, like education status and residency periods, which seemingly also contribute to negative under-five diarrhoea outcomes; c) Study findings should be used to continue improvements of the camp's potable drinking water supply system; d) Improvements relative to NGO tap use, tap chlorination practices and subsequent resident behaviors should follow guidelines which adopt the CDC's Safe Water System.

\section{CONCLUSION}

Children under five living in households provided a safe storage drinking water container were better protected against diarrhoea morbidity than those 
without. Most likely this is due to diminished and sustained lower $E$. coli readings evidenced by drinking water quality tests within intervention households, when compared with control group households. Thus, microbiological water quality is protected against contamination by the introduction of improved safe storage water containers which use sealed tops and spigots. Contamination of household drinking water, especially from E. coli, is a very common occurrence in refugee shelters, such as Mae La, and chlorination alone is an inadequate protection mechanism against diarrhoea disease.

\section{ACKNOWLEDGEMENTS}

The authors are grateful to all staff members of the following organizations in Thailand: the Centers for Disease Control and Prevention (CDC), International Organization for Migration (IOM), the field workers and participants in the study.

\section{REFERENCES:}

1. Kosek M, Bern C, Guerrant RL. The global burden of diarrhoeal disease, as estimated from studies published between 1992 and 2000. Bulletin of the world health organization. 2003;81:197-204. [LINK]

2. Tambekar DH, Mahore AJ. Studies on Personal and Domestic Hygienic Practices in Storage and Handling of Drinking Water in Houses. Pollution research. 2005;24(2):377.

3. Lindskog RU, Lindskog PA. Bacteriological contamination of water in rural areas: an intervention study from Malawi. The Journal of tropical medicine and hygiene. 1988 Feb;91(1):1-7. [LINK]

4. Trevett AF, Carter RC, Tyrrel SF. The importance of domestic water quality management in the context of faecal-oral disease transmission. Journal of Water and Health. 2005 Sep 1;3(3):259-70. [LINK]

5. Oswald WE, Lescano AG, Bern C, Calderon MM, Cabrera L, Gilman RH. Fecal contamination of drinking water within peri-urban households, Lima, Peru. The American journal of tropical medicine and hygiene. 2007 Oct 1;77(4):699704. [LINK]

6. Nala NP, Jagals $P$, Joubert $G$. The effect of a wa- ter-hygiene educational programme on the microbiological quality of container-stored water in households. Water SA. 2003;29(2):171-6. [LINK]

7. WORLD HEALTH ORGANIZATION (WHO). Household Water Treatment and Safe Storage Following Emergencies and Disasters. South Asia Earthquake and Tsunami. 2002.

8. VanDerslice J, Briscoe J. All coliforms are not created equal: A comparison of the effects of water source and in-house water contamination on infantile diarrheal disease. Water resources research. 1993 Jul 1;29(7):1983-95. [PDF]

9. Hammad ZH, Dirar HA. Microbiological examination of sebeel water. Appl. Environ. Microbiol.1982 Jun 1;43(6):1238-43. [PDF]

10. Roberts L, Chartier Y, Chartier O, Malenga G, Toole M, Rodka $\mathrm{H}$. Keeping clean water clean in a Malawi refugee camp: a randomized intervention trial. Bulletin of the World Health Organization. 2001;79:280-7. [LINK]

11. Trevett AF, Carter RC, Tyrrel SF. The importance of domestic water quality management in the context of faecal-oral disease transmission. Journal of Water and Health. 2005 Sep 1;3(3):259-70.

12. WHO, (2006): Guidelines for Drinking water Quality. Geneva: WHO.

13. Vendrell PF, Atiles JH. Household water quality: Coliform bacteria in your water. [PDF]

14. Bartram J, Ballance $R$, editors. Water quality monitoring: a practical guide to the design and implementation of freshwater quality studies and monitoring programmes. CRC Press; 1996 Jul 25.

15. Biennial report (2009-2010) MoPH, Thailand, Centers for Disease Control and Prevention $(C D C)$, and the Thai MoPH-CDC Collaboration , Ministry of Public Health, Thailand.

16. Morris SS, Cousens SN, Lanata CF, Kirkwood BR. Diarrhoea-defining the episode. International Journal of Epidemiology. 1994 Jun 1;23(3):61723. [DOI] 